\title{
WEE2 Mutations as a Cause of Complete Fertilization Failure (CFF) When it is the Female Factor Responsible for CFF- A Short Communication
}

\author{
Kulvinder Kochar Kaur ${ }^{1 *}$, Gautam Allahbadia ${ }^{2}$ and Mandeep Singh ${ }^{3}$ \\ ${ }^{1}$ Scientific Director, Dr Kulvinder Kaur Centre For Human Reproduction, India \\ ${ }^{2}$ Scientific Director, Ex-Rotunda-A Centre for Human reproduction, India \\ ${ }^{3}$ Consultant Neurologist, Swami Satyanand Hospital, India
}

Submission: December 09, 2019; Published: December 18, 2019

*Corresponding author: Kulvinder Kochar Kaur, Scientific Director, Dr Kulvinder Kaur Centre For Human Reproduction, India

\begin{abstract}
Normally following in vitro fertilization(IVF), one comes across 1-4\% of patients with complete fertilization failure(CFF), which usually can be overcome by shifting to intracytoplasmic sperm injection(ICSI).We have tried to explain the factors responsible for normal fertilization and earlier we had shown how calcium ionophores could be used to activate oocytes when oocyte activation was a problem. But still despite ICSI in some cases of unexplained fertility one cannot pinpoint the cause of FF. Here we have illustrated the role of WEE2 gene found essential in mammals for oocyte activation in preovulatory follicles whose mutations might explain the occurrence of CFF in women with unexplained infertility.

Keywords: CFF; IVF; ICSI; Unexplained infertility; WEE2 gene; WEE2 gene mutations

Abbreviatations: CFF: Complete Fertilization Failure; IVF: In Vitro Fertilization; ICSI: Intracytoplasmic Sperm Injection; ART: Artificial Reproductive Technology
\end{abstract}

\section{Mini Review}

For fertilizaton to occur, a complex steps of processes occur like the spermatozoa binding to the zona pellucida (ZP), and must go through an acrosome reaction, then invade the ZP, fuse with the oolemma, activate the oocyte and develop pronuclei (PN) [1]. Basically, it is the development of a diploid zygote following interaction as well as fusion of the 2 haploid gametes that stimulates a cascade of processes that are necessary for the formation of a zygote and pregnancy to occur [2-5]. There are 2 parts of the fertilization i) the fusion of the gametes and ii) the activation of oocyte. Egg activation includes calcium oscillation, cortical granule exocytosis, and formation of the second polar body (2PB) and 2 pronuclei (PN) [6-8], that points that once fertilization of oocytes is finished, oocytes have finished meiosis II and would get into the interphase of mitosis [9]. As far as artificial reproductive technology [ART] is concerned complete fertilization failure by definition is all of the collected mature oocytes fail to develop PN within 15-18h of insemination [10,11].
Complete fertilization failure (CFF) is one of the reasons for female infertility. The clinical incidence of $\mathrm{FF}$, particularly $\mathrm{CFF}$ with nonfertilized embryos is $1-4 \%$ in in vitro fertilization (IVF), and $1.4 \%$ in intracytoplasmic sperm injection (ICSI) $[12,13]$.

Routinely during in vitro fertilization (IVF), FF occurs mainly at the time of sperm/oocyte binding as well as fusion [14-16], yet the ZP and oolemma barriers may be surpassed with the utilization of intracytoplasmic injection (ICSI) [17]. But FF following ICSI continues to remain a problem. CFF following ICSI, in case when minimum of 3 or $>$ mature oocytes are present, takes place in $1-5 \%$ of ICSI cycles $[18,19]$. Genetic cause was thought of specially in cases with recurrent CFF or poor fertilization following ICSI. Earlier work demonstrated that ICSI reduced the rate of CFF with unexplained infertility, still occasional patients do present with CFF [20]. Earlier literature has pointed that the mutations of sperm activation factors gene PLCZ1, that results in great abnormal $\mathrm{Ca}^{2+}$ transients in oocyte, might result in $\mathrm{FF}$ 
following ICS [21]. But the oocytes-associated factors leading to FF are mostly not found in humans. TLE6 has been correlated with the phenotype of FF [22] and recently it was documented that homozygous mutations in WEE2 in a recessive inheritance pattern were detected in 4 women with infertility presenting with CFF [23]. WEE2 is an oocytes-specific protein tyrosine kinase which phosphorylates as well as inhibits CDC2 and works as a crucial controller of meiosis at the time of prophase I and metaphase II [24] that gets encoded by the WEE2 gene. An earlier study revealed that WEE2 is expressed only in oocytes and attain s the maximum amounts in preovulatory follicles following collection at the time of folliculogenesis [25].

It seemed to be from maternal origin that remains conserved between variety of species. Different mammalian species study like in mouse, cat and pig it was shown that it was required for GV stage quietening. It is needed for metaphase II exit at the time of egg activation by phosphorylation of CDC2 to aid in PN development. Further it is needed to sustain germinal vesicle stage arrest in oocytes [26-29]. In mouse oocytes, if Wee2 was downregulating utilizing morpholino oligonucleotide it resulted in prevention of PN generation during fertilization [9].The mutations rate in WEE2 is not understood, and if any other kind of mutation exists or is present regarding the presence of any other phenotype warrants more evaluation.

Thus Dai et al. [16] Evaluated 24 Chinese women undergoing ART, having recurrent FF or poor fertilization following ICSI. These women had a whole-exome sequencing as well as candidate mutations were confirmed by Sanger sequencing. Single cell reverse transcription was utilized to forecast the effect of missense mutations on secondary protein structure. To evaluate the protein amounts of WEE2 and phosphorylated CDC2 utilizing Immunofluorescence. Biallelic mutations in WEE2 were observed in $5 / 24(20.8 \%)$ Chinese women with FF or poor fertilization. Of these subjects a novel splice-site mutation, 2 novel missense mutations as well as earlier documented frame-shift mutation were observed. Splicing mutations c.1136-2A $>$ G of WEE2 led to changes in the reading frame and added a premature stop codon (p. Gly 379Glu fs*6/p.Asp380Leufs ${ }^{*} 39$ ).The missense mutationsc. 585G $>$ C (p.Lys195 Asn) and c.1228C $>$ T (p.Arg410Trp) developed clear alterations in secondary protein structures. By immunostaining it was shown that mutated WEE2 caused a loss of phosphorylated CDC2. Slight differences were seen in phenotypes of women who carried WEE2 mutation, differing from FF to poor fertilization. Thus concluding that novel mutations in the known causative gene WEE2 were detected in 5/24 women with FF or poor fertilization, pointed to a high prevalence of WEE2 mutations in Chinese women who faced FF or poor fertilization [30].

Zhou et al. [30], tried to find if any variations in the WEE2 (WEE1 homolog 2, alias WEE1B) gene, that has been understood to work in the generation of PN, result in FF.90 Infertile women presenting with recurrent cycles of PN generation failure going through IVF and/or ICSI therapy as well as 200 fertile controls had genomic DNA extraction from the peripheral blood. The whole exons of WEE2 were amplified utilizing polymerase chain reaction (PCR) and further Sanger Sequencing. 5 patients were isolated who were subjected to homozygous variants of WEE2: case1(belonging to a consanguineous family) with homozygous frameshift variant: c.293_294insCTGAGACACCAGCCCAACC (p.Pro98ProfsX2); Case 2 with homozygous missense variant:c.1576T>G(p.Tyr526Asp); and 3 cases with compound-hetrozygous variants: case 3: c.991 C>A (p.His331Asn) and c.1304_1307delCCAA (p.Thr 435 Met fsX31)case 4:c.341_342del AA (p.Lys 114Asn fsX20) and c.864G>C (from case 4 that has been documented earlier as rare single nucleotide polymorphisms(SNPs), the other 6 variants were novel and forecasted by software to be harmful. Parental genotypes of case 1 and case 2 pointed that the homozygous variants were inherited in an autosomal recessive way. All of the variants found were not there in the control cohort. Thus concluding that novel variants identified in WEE2, that is autosomal recessive inherited, might be associated with repeated PN generation failure and female infertility [31].

\section{Conclusion}

Earlier we had reviewed how Calcium Ionophores might be utilized for Artificially Activating Oocyte in Cases of Persistent Fertilization failure Despite ICSI [32]. Thus, concluding in cases of CFF in women despite ICSI one should try to rule out WEE2 mutation and see if Calcium Ionophores for Artificially Activating Oocyte helps in these Cases of Persistent Fertilization failure.

\section{References}

1. Swain JE, Pool TB (2008) ART failure: oocyte contributions to unsuccessful fertilization. Hum Reprod Update 14(5): 431-446.

2. Anifandis G, Messini C, Dafopoulous K, Sotinou S, Messinis I, et al. (2014) Molecular and cellular mechanisms of sperm-oocyte interactions opinion in relative to in vitro fertilization (IVF). Int J Mol Sci 15(7): 12972-12997.

3. Clift D, Schuh M (2013) Restarting life: fertilization and the transition from meiosis to mitosis. Nat Rev Mol Cell Biol 14(9): 549-562.

4. Neri QV, Lee B, Rosenwaks Z, Machaca K, Palermo GD, et al. (2014) Understanding fertilization through intracytoplasmic injection ( ICSI). Cell Calcium 55(1): 24-37.

5. Wassarman PM, Jovine L, Litscher ES (2001) A profile of fertilization in mammals. Nat Cell Biol 3(2): E59-E64.

6. Xu YR, Yang YX (2017) Calcium influx and sperm evoked Calcium responses during oocyte maturation and egg activation. Oncotarget8(51): 89375-89390.

7. Horner VL, Wofner MF (2008) Transitioning from egg to embryo: triggers and mechanism of egg activation. Des Dyn 237(3): 527-544.

8. Ducibella T, Huneau D, Angelichio E, Xu Z, Schultz RM, et al. (2002) Egg to embryo Transition is driven by differential responses to $\mathrm{Ca}^{2+}$ oscillation number. Dev Biol 250(2): 280-291.

9. Oh JS, Susor A, Conti M (2011) Protein tyrosine kinase WEE1B is essential for metaphase II exit in mouse oocytes. Science332(6028): $462-465$. 
10. Kahyaoglu I, Demir B, Turkkani A, Cinar O, Dilbaz S, et al. (2014) Totalfertilization failure: is it the end of the story? J Asst Reprod Genet 31(9): 1155-1160.

11. Shinar S, Almong B, Levin I, Schwartz T, Amit A, et al. (2014) Total fertilization failure in intracytoplasmic injection cycles -classification and management. Gynaecol Endocrinol 30(8): 593-596.

12. Tosti E, Menenzo Y (2016) Gamete activation: basic knowledge and clinical applications. Hum Reprod Update 22(4): 420-439.

13. Lee SH, Lee JH, Park YS, Yang KM, Lim CK, et al. (2017) Comparison of clinical outcome between in vitro fertilization (IVF) and intracytoplasmic sperm injection (ICSI) in IVF- ICSI split stimulation cycles. Clin Exp Reprod Med 44(2): 96-104

14. Liu D, Baker HW (2000) Defective sperm-zona pellucida interaction: a major cause of failure of fertilization in clinical in vitro fertilization. Hum Reprod 15(3): 702-708.

15. Rawe VY, Olmedo SB, Nodar FN, Doncel GD, Acosta AA, et al. (2000) Organization defects and abortive activation in human oocytes after IVF and ICSI failure. Mol Hum Reprod 6(6): 510-516.

16. Dai C, Hu L, Gong F, Tan Y, Cai S, Zhang S, et al. (2019) ZP2 pathogenic variants cause in vitro fertilization failure andfemale infertility. Genet Med 21(2): 431-440.

17. Van der Westerlaken L, HelmerhorstF, Dieben S, NaaktgeborenN (2005) intracytoplasmicsperminjection as a treatment ofunexplained total fertilization failure or low fertilization after conventional in vitro fertilization. Fertil Steril 83(3): 612-617.

18. Nasr-Esfahani MH, Deemeh MR, Tevalee M (2010) Artificial oocyte activation and intracytoplasmic sperm injection. Fertil Steril 94(2): 520-526.

19. Johnson LN, Sasson IE, Sammel MD, Dokras A (2013) Does intracytoplasmic sperm injection improve the fertilization rate and decrease the total fertilization failure in couples with well defined unexplained infertility? A Systematic Review and Meta-analysis. Fertil Steril 100(3): 704-711.

20. Layman LC (2013) The genetic basis of female reproductive disorders: etiology and clinical testing. Mol Cell Endocrinol 370(3): 138-148.

21. Kashir J, Konstantinidis M, Jones C, Lemmon B, Lee HC, et al. (2012) A maternally inherited autosomal point mutation in human phospholipase C zeta (PLC zeta) leads to male infertility. Hum Reprod 27(1): 222-231.

22. Alazami AM, Awad SM, Coskun S, Al-Hassan S, Hijazi H, et al. (2015) TLE6 mutation czauses the earliest known human embryonic lethality. Genome Biol 16: 240.

23. Sang Q Li B, Kuang Y, Wang X, Zhang Z, et al. (2018) Homozygous mutations in WEE 2 cause fertilization failure and female infertility. Am J Hum Genet 102(4): 649-657.

24. Han SJ, Conti M (2006) New pathways from PKA to the Cdc2/cyclin B complex in oocytes: Wee1B as a potential PKA substrate. Cell Cycle 5(3): 227-231.

25. Hanna CB, Yao S, Patta MC, Jensen JT, Wu X, et al. (2010) WEE2 is an oocyte-specific meiotic inhibitor in rhesus macaque monkeys. Biol Reprod 82(6): 1190-1197.

26. Han SJ, Chen R, Pafronetto MP, Conti M (2005) Wee1Bis an oocytespecific kinase involved inthe control of meiotic arrestin the mouse. Curr Biol 15(18): 1670-1676.

27. Kim YG, Kim DH, Song SH, Lee KL, Yang BC, et al. (2015) Wee1B depletionpromotes nuclear maturationof canine embryos. Theriongenology 83: 546-52.

28. Oh JS, Han SJ, Conti M (2010) Wee1B, Myt 1 and Cdc25 functionin distinct compartmentsof the mouseoocytesto control meiotic resumption. J Cell Biol 188(2): 199-207.

29. Shimaoka T, Nishimura T, Kano K, Naito K (2009) Critical effect of pig Wee1B on the regulation ofmeiotic resumption in porcine immature oocytes. Cell Cycle 8(15): 2375-2384.

30. Dai S, Zheng W, Dai C, Guo J, Lu C, et al. (2019) New biallelic mutation s in WEE2: expanding the spectrum of mutation that cause fertilization failure or poor fertilization. Fertil Steril 111(3): 510-517.

31. Zhao S, Chen T, Yu M, Bian Y, Cao Y, et al. (2019) Novel WEE2 gene variants identified in patients with fertilization failure and female fertility. Fertil Steril 111(3): 519-526.

32. Kulvinder Kochar Kaur, Allahbadia GN, Singh M (2018) Role of calcium ionophores for artificially activating oocyte in cases of persistent fertilization failure despite icsi-a short commentary. Open Access Journal of Gynecology and Obstetrics 1(2): 11-12.

\section{Your next submission with Juniper Publishers will reach you the below assets}

- Quality Editorial service

- Swift Peer Review

- Reprints availability

- E-prints Service

- Manuscript Podcast for convenient understanding

- Global attainment for your research

- Manuscript accessibility in different formats

( Pdf, E-pub, Full Tsext, Audio)

- Unceasing customer service

Track the below URL for one-step submission https://juniperpublishers.com/online-submission.php 